\title{
How much of a problem is bullying at school?
}

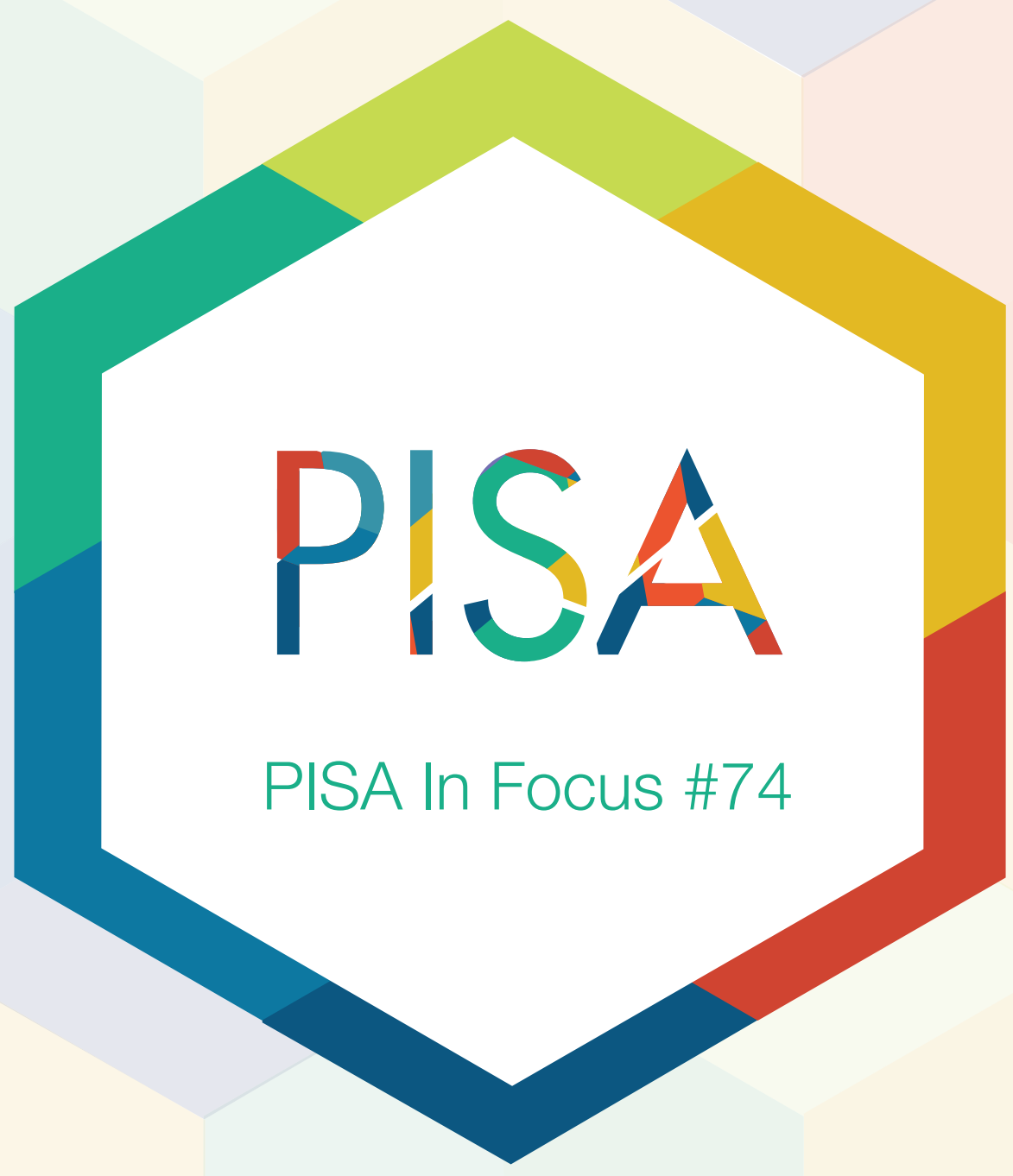


- On average across OECD countries, $4 \%$ of students reported that they are hit or pushed and $8 \%$ reported that they are victims of nasty rumours at school at least a few times per month.

- Students in schools where bullying is more frequent perform worse than students in schools where bullying is less frequent.

- Bullying is more frequent in schools where students reported a poor disciplinary climate and negative relationships with teachers.

"Dodging blows, being tripped up and spat at. Closing your ears to insults and mockery. Keeping an eye on your bag and your hair. Holding back the tears. Again and again... I don't want my parents to know how pathetic I am, and think they've given birth to a piece of crap (Emilie, 13 years old)". Emilie's story illustrates the pain experienced by thousands of children and adolescents who fight an internal battle every day to get up, get ready and go to school. Some consider bullying a normal part of growing up, and that being the victim of bullying might even build resilience in adults. But there is often more to unkind words and offensive online posts than "just joking around". Both physical and relational violence leave deep emotional scars, and not just on victims, but also on perpetrators and bystanders.

\section{Thousands of students reported they are victim of relational or physical bullying.}

For the first time, the 2015 round of PISA collected data on students' exposure to bullying. These data show that bullying is widespread. On average across OECD countries, around $11 \%$ of students reported that they are frequently (at least a few times per month) made fun of, $8 \%$ reported that they are frequently the object of nasty rumours in school, and $7 \%$ reported that they are frequently left out of things. On average across OECD countries, around $4 \%$ of students reported that they are hit or pushed at least a few times per month, although this percentage varies from around $1 \%$ to $9 \%$ across countries. Similar proportions of students reported that they are threatened by others, or that their belongings are destroyed or taken away by other students. On average across OECD countries, about one in five students is frequently the victim of at least one of these acts of bullying.

\section{Percentage of students who reported being bullied frequently (at least a few times per month)}

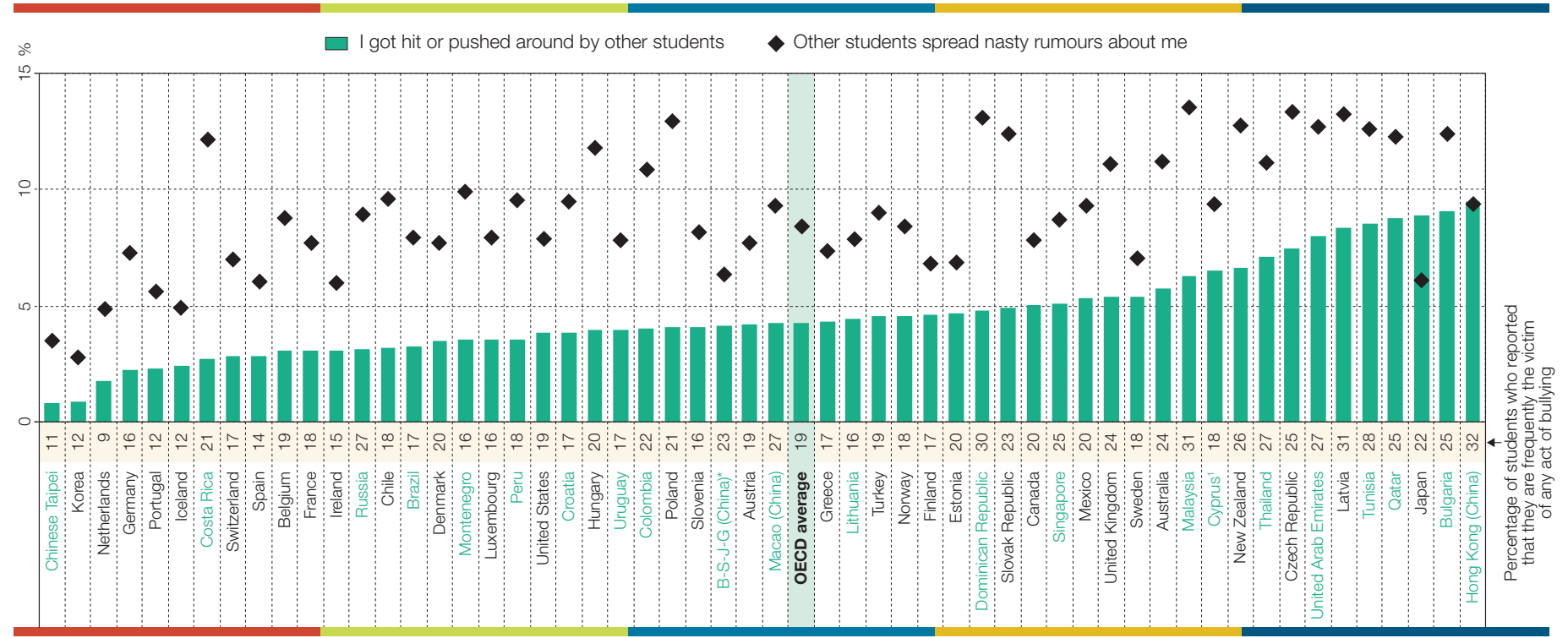

* B-S-J-G (China) refers to the four Chinese provinces and municipalities that participated in PISA 2015: Beijing, Shanghai, Jiangsu and Guangdong. 1. Note by Turkey: The information in this document with reference to "Cyprus" relates to the southern part of the Island. There is no single authority representing both Turkish and Greek Cypriot people on the Island. Turkey recognises the Turkish Republic of Northern Cyprus (TRNC). Until a lasting and equitable solution is found within the context of the United Nations, Turkey shall preserve its position concerning the "Cyprus issue".

Note by all the European Union Member States of the OECD and the European Union: The Republic of Cyprus is recognised by all members of the United Nations with the exception of Turkey. The information in this document relates to the area under the effective control of the Government of the Republic of Cyprus. Countries and economies are ranked in ascending order of the percentage of students who report that they got hit or pushed around by other students at least a few times per month.

Source: OECD, PISA 2015 Database, Table III.8.1. 
Boys were more likely than girls to report being hit or pushed, but girls tend to be victims of nasty rumours more often than boys. Children of immigrants who had arrived in the host country at or after the age of 12 face a higher risk of being bullied than non-immigrant students and than immigrant students who had arrived in the country in which they sat the PISA test before the age of 12. In 29 countries and economies with available data, students in disadvantaged schools were more likely to report being a victim of bullying than students in advantaged schools. Only in Japan, Korea and Macao (China) were students in advantaged schools more likely than students in disadvantaged schools to report being bullied.

\section{The prevalence of bullying at school can affect students' performance.}

Being bullied can negatively affect academic achievement because it influences students' capacity to focus on academic tasks. Schools where the incidence of bullying is high by international standards (more than $10 \%$ of students are frequently bullied) score 47 points lower in science, on average, than schools where bullying is less frequent (schools where less than $5 \%$ of students are frequently bullied). This difference in performance between the two types of schools remains substantial (around 25 score points) even after accounting for differences in schools' socio-economic profile. These relationships suggest that bullying can both stem from and may exacerbate students' disengagement with school and underperformance.

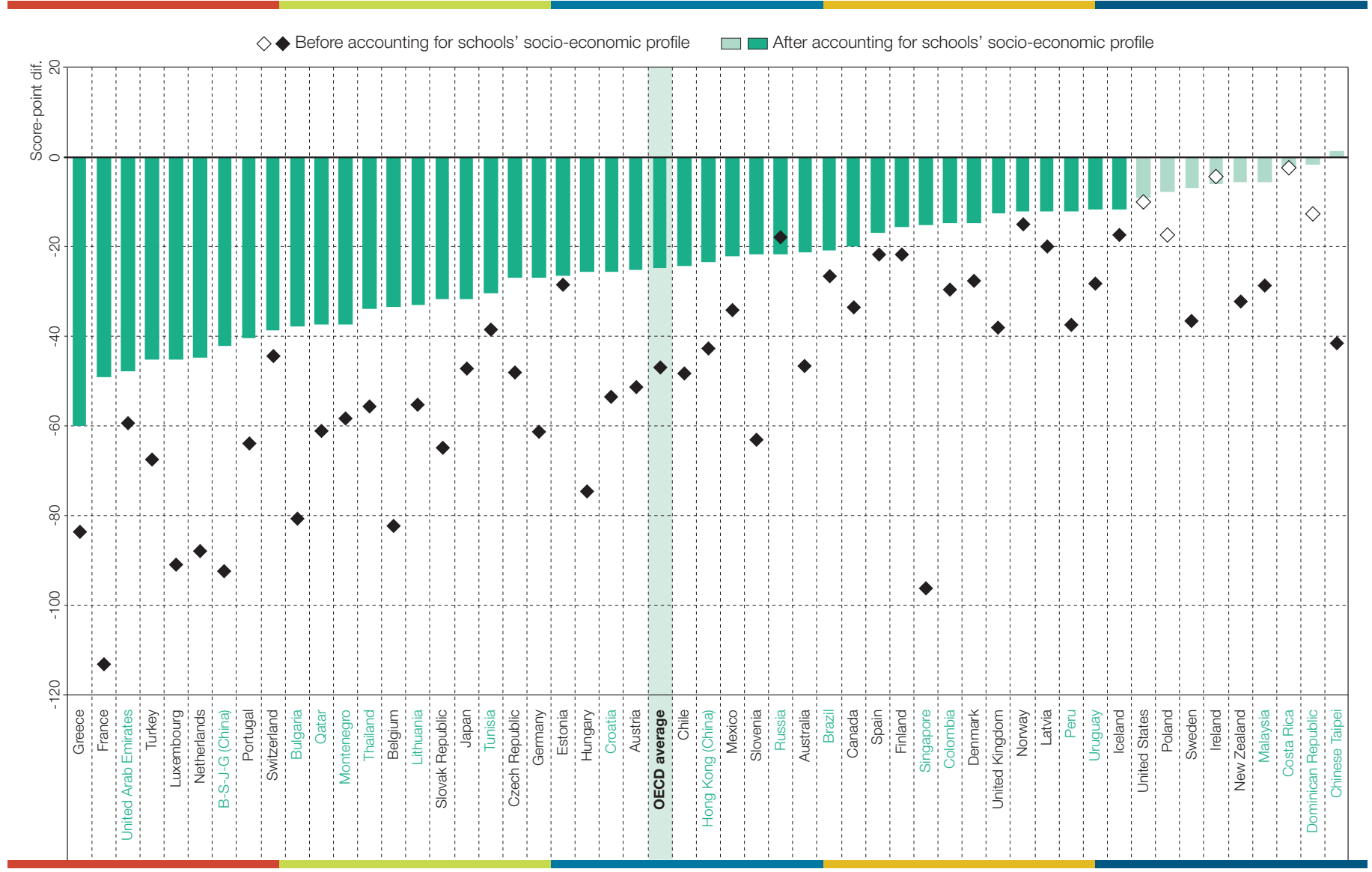

1. Schools with a high prevalence of bullying are those where more than $10 \%$ of students are frequently bullied. Schools with a low prevalence of bullying are those where $5 \%$ of students or less are frequently bullied. A student is frequently bullied if he or she is in the top $10 \%$ of the index of exposure to bullying among all countries/economies.

Note: Statistically significant values are marked in a darker tone.

Countries and economies are ranked in ascending order of the score-point difference in science performance between schools with a high prevalence of bullying and schools with a low prevalence of bullying, after accounting for schools' socio-economic profile.

Source: OECD, PISA 2015 Database, Table III.8.10. 


\section{Bullying has long-term consequences for students' well-being.}

Being bullied is one of the most severe forms of stress that children can experience. Prolonged exposure to the stress hormone cortisol can alter parts of the brain architecture, such as the amygdala and the hippocampus, that are critical for regulating emotions. These negative effects are more problematic for young people because the body's system for handling stress is particularly sensitive during this period of development.

Students who are frequently bullied have clear difficulties finding their place at school. They tend to feel unaccepted and they often forego making friends. On average across OECD countries, about $42 \%$ of students who are frequently bullied - but only $15 \%$ of students who are not frequently bullied - reported feeling like an outsider at school. Bullying can lead to depression, anxiety and sleep disorders. About $26 \%$ of frequently bullied students reported relatively low satisfaction with life (a value less than or equal to 4 on a scale from 0 to 10). Only around $10 \%$ of students who are not frequently bullied reported such low satisfaction with their life. In Korea, Turkey and the United Kingdom, more than one in three frequently bullied students reported low satisfaction with life.

Victims of bullying often decide to stay out of school. On average across OECD countries, about $9 \%$ of frequently bullied students (but only $4 \%$ of students who are not frequently bullied) reported that they had skipped school more than three or four times in the two weeks prior to the PISA test.

\section{Relationship between being frequently bullied and students' outcomes OECD average}

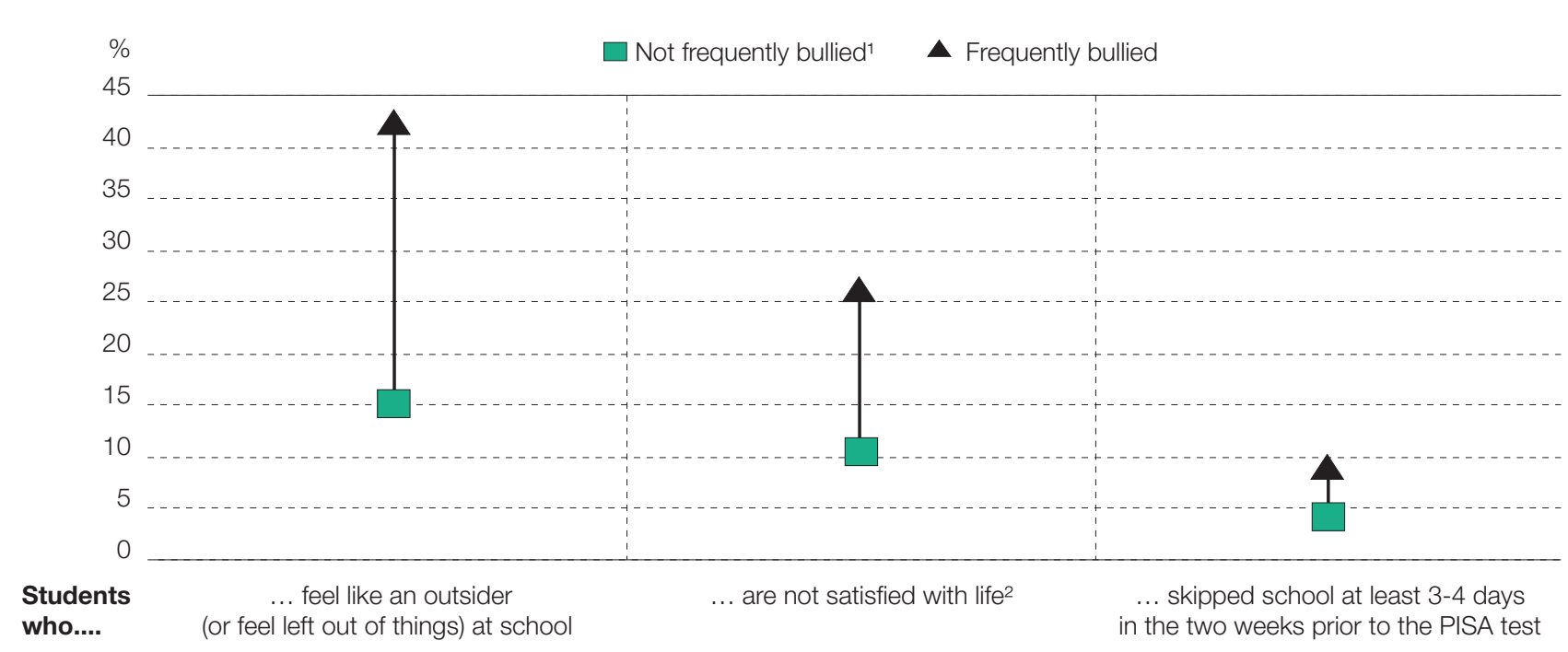

1. A student is frequently bullied if he or she is in the top $10 \%$ of the index of exposure to bullying among all countries/economies.

2. A student is classified as "not satisfied" with life if he or she reported between 0 and 4 on the life-satisfaction scale. The life-satisfaction scale ranges from 0 to 10.

Source: OECD, PISA 2015 Database, Table III.8.15. 


\section{To combat bullying, improve the school climate.}

Educators can reduce the incidence of bullying by creating a climate of support and empathy both in and outside of the classroom. Schools with a low incidence of physical and relational violence tend to have more students who are aware of school rules, believe that these rules are fair, and have positive relations with their teachers.

When they work in a structured and orderly environment, students feel more secure, become more engaged with school work, and are less inclined to engage in risky behaviours. On average across OECD countries, the proportion of frequently bullied students is about 6 percentage points larger in schools with a poor disciplinary climate (worse than the country average) than in schools with a good disciplinary climate (better than the country average), after accounting for schools' socio-economic profile.

PISA data also show that students who attend schools where perceptions of teachers' unfair behaviour are pervasive (where the share of students who feel they are disciplined more than other students, or who feel that they are ridiculed or insulted by their teachers is above the country average) are 12 percentage points more likely to be frequently bullied than students in schools where these perceptions are not as pervasive (where the share of students who report such treatment from their teachers is below the country average). This relationship is only partly related to other characteristics of the schools, such as average performance or socio-economic profile. These findings suggest that teachers might help limit bullying by communicating clearly to students that they will not tolerate any form of disrespectful behaviour, and by acting as role models in the classroom. Incorporating bullying-prevention modules in initial teacher training can ensure that all teachers have basic preparation in detecting and reacting to different acts of bullying. Another important strategy against bullying is building strong partnerships between schools and parents.

\section{The bottom line}

School leaders, teachers, parents and students need to work together to improve the school climate and reduce the incidence of bullying. Whole-ofschool prevention and intervention strategies can make everyone responsible for supporting victims and confronting bullies. 


\section{For more information}

Contact: Mario Piacentini (Mario.Piacentini@oecd.org)

See: PISA 2015 Results (Volume III): Students' Well-Being, PISA, OECD Publishing, Paris,

http://dx.doi.org/10.1787/19963777.

Coming next month: Does the quality of learning outcomes fall when education expands to include more disadvantaged students?

This paper is published under the responsibility of the Secretary-General of the OECD. The opinions expressed and the arguments employed herein do not necessarily reflect the official views of OECD member countries.

This document and any map included herein are without prejudice to the status of or sovereignty over any territory, to the delimitation of international frontiers and boundaries and to the name of any territory, city or area.

This work is available under the Creative Commons Attribution-NonCommercial-ShareAlike 3.0 IGO (CC BY-NC-SA 3.0 IGO). For specific information regarding the scope and terms of the licence as well as possible commercial use of this work or the use of PISA data please consult Terms and Conditions on www.oecd.org. 